\title{
Predicting Economic Crisis using Financial to Real Sector Disproportion: Theory And Evidence
}

\author{
Anna Svirina, Elena Parfenova and Olga Shindor \\ Kazan National Research Technical University, Chistopol, Russia \\ Correspondence should be addressed to: Anna Svirina; anna_svirina@yahoo.com \\ Received date: 10 September 2015; Accepted date: 18 January 2016; Published date: 16 March 2016 \\ Academic Editor: Costin Octavian Sorici
}

Copyright (C) 2016. Anna Svirina, Elena Parfenova and Olga Shindor. Distributed under Creative Commons CC-BY 4.0

\begin{abstract}
The paper analyzes the possibility of implementing the financial/real sector ratio as a predictor of economic crisis using evidence based upon US economy data (volumes of financial and real sectors of the economy estimated for each year between 1867 and 2014). The study suggests that the implementation of this predictor requires the use of quantum-based approach (i.e. Heisenberg uncertainty principle) aiming to evaluate disproportions between financial and real sectors of the economy to use the corresponding ratio as an indicator of upcoming economic crisis. Thus, the suggested theory is based upon developmental theory and quantum theory, while the evidential part of the study includes the evaluation of financial and real sectors' dynamics by means of graph analysis and wavelet transform. The quantitative results support the hypothesis that the ratio between the financial and real sectors of the economy, assessed by means of wavelet transform, can be used as a predictor of economic crisis 4-5 years prior to its occurrence. Wavelet transform also allows indicating the possible intensity of the upcoming crisis.
\end{abstract}

Keywords: economic cycles, economic crisis, quantum economics, financial sector, real sector.

\section{Introduction}

The study of Cecchetti and Kharroubi (2015) had indicated that the growth of financial sector has a negative impact on real sector economy growth, which can be found in almost every sector of the economy. Their findings distort the basic equation describing economic equilibrium: Fischer's equation, and thus open the door for seeking a new theory aiming to explain contemporary economy development. Similar results were acquired by Studwell
(2013), who emphasized the need to control the financial sector in order to grow, and named liberalization of financial sector one of the most important obstacles for economic growth - in the case of the most promising Asian economies. Both studies outline the role of the financial sector and seem to overthrow the dominance of Fischer's equation: if not controlled, the financial sector can grow much bigger and suppress the real sector. Still, both studies prove the fact, but do not shed light on the

Cite this Article as: Anna Svirina, Elena Parfenova and Olga Shindor (2016), " Predicting Economic Crisis using Financial to Real Sector Disproportion: Theory and Evidence," Journal of Economics Studies and Research, Vol. 2016 (2016), Article ID 831476, DOI: 10.5171/2016.831476 
origins of such interactions between financial and real sectors.

In the study of 2014 (Svirina et al., 2014), it is proposed that the stage of the economic cycle at a time point can be defined on the basis of the ratio between the financial and real sectors of the economy. A growth stage is observed when there is parity between those sectors, which means that the amount of consumption within the economic system is equal to the amount of investment. A recession begins when the financial and real sectors become highly unbalanced - and this comes in line with the findings of Cecchetti and Kharroubi who captured the quantitative proof of such misbalance.

Putting together these findings, we suggest that the phenomenon Cecchetti and Kharroubi (2015) are observing relates to the end of the economic cycle, and indicates that currently the disproportion between financial and real sectors is large enough to say we are in the world of quantum economy. We have tested this hypothesis both with statistical analysis and using wavelet transform: the results can be found below.

\section{Literature Review}

Theoretical methodologies addressing and incorporating economic cycles (and economic crises as a part of economic cycle) were designed to explain typical economic fluctuations over time and to systematize the diverse and inconsistent retrospective data on economic development. Currently, there are a number of theories premised upon economic cycles that analyze problems ranging from global economic development to single enterprise development. Their common feature is that they posit that development is cyclical rather than pendular (Hansen, 1951).

The main measuring parameter implemented in cyclical-wave methodology is time, which is seen as the indicator that characterizes a sequence of specific events. According to this parameter, the length of social systems' cycles can be divided into three groups: the macrolevel, the mesolevel, and the microlevel. Thus, the duration of the "industry cycles" introduced by S. Kuznets (Kuznets, 1965) or the "innovation lifecycle" introduced by J. Schumpeter (Schumpeter, 1939) can vary from a few months to a few decades. Karl Marx's “cycle of main capital turnover" (Marx, 1990) can last 50-60 (or more) years-the duration of the cycle depends on the period of service that is appropriate for a certain type of main capital. Kondratiev's waves (Kondrat'yev, 1989), which are considered by researchers to be international phenomena, have a duration of 50-60 years. There have also been a number of attempts to identify the relationship between wars and business cycles or between business cycles and the dynamics of industrial production. A number of studies have attempted to link values and business cycles (Eusepi \& Preston, 2011). It is also notable that the studies that link noneconomic factors with business cycles typically employ theories that employ Kondratiev's waves, which are usually associated with global economic cycles. All of the above mentioned cycles are bound to include a stage of economic crisis, but the length of growth, stagnation and crisis periods still remain uncertain, and existing research does not suggest any specific approach towards the estimation of cycle length and does not propose clear identification of global economic cycles' preconditions, and evaluates a significant number of possible pre-conditions.

The other important issue to study in order to reveal possible pre-conditions for crisis is uncertainty evaluation. As suggested by existing literature, uncertainty level should be estimated in order to improve the quality of economic and managerial predicting models that had for a long while been one of the major problems of business research. Analysis of existing literature reveals that the main tools used to reduce uncertainty in measuring company performance include: use of factor analysis and definition of the main factors affecting the result variable (Lorsh \& Allen, 1973), defining predictors of economic agents' behavior (Downey \& Slocum, 1973), implementation of smoothing and buffering (Lev, 1975), estimation of shocks to define probable uncertainties (Jurado et al., 2013), use of appropriate statistical distribution (Sweeney et al.,1987) or external forecasters (Boero et al., 2008). Still, the suggested instruments, as it is proven by the mentioned authors, can be used only in certain cases - while in the 
other situations they do not provide any effect in reducing uncertainty.

The other proposition made in Svirina et al. (2014) considers the following. Analysis of global economic system development in the last 40 years shows that a number of fundamental principles of classical political economy, such as, for example, the deterministic laws of supply and demand (Goncaves, 2012) do not explain facts provided by empirical evidence. This was outlined by a number of research studies that tried to develop an alternative model of economic growth on the basis of quantum principles (Cencini, 2001; Sobey, 2012; Ternyik, 2012); and on the basis of their research we make the following proposal: classical political economy is based on deterministic principles, while modern economy has a quantum nature - therefore the main principles of classical theory are proven in the modern world only with a certain probability.

\section{Methodology}

Heisenberg principle states that "the position and the velocity of an object cannot both be measured exactly, at the same time, even in theory" (Heisenberg, 1927), and is considered by physicists to be a consequence of wave/particle duality that appears on the microlevel of the physical world (an illustration of this principle can be seen on Figure 1).

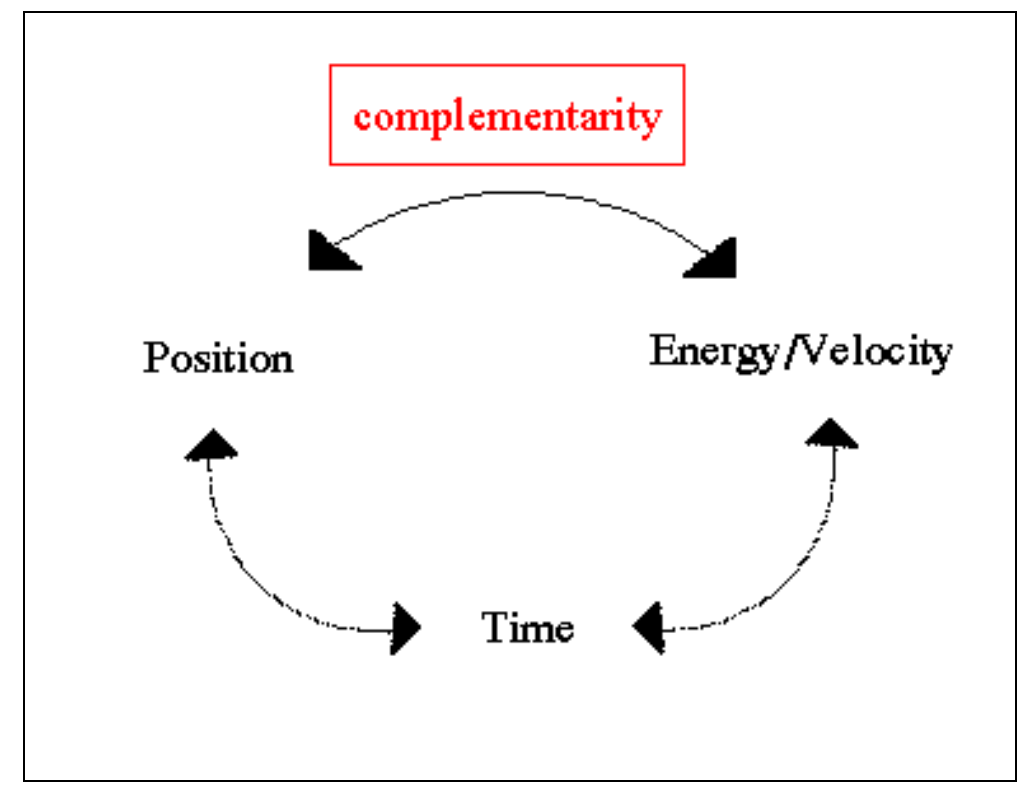

Figure 1: Visualization of Heisenberg principle (Uncertainty principle, 2013)

In physics this principle applies to estimation of position and velocity of electron, and an analogue can be found in socio-economic systems when we try to measure the potential (an analogue of energy/velocity) and efficiency (actual position) of socio-economic systems. The main effect retrieved from physics is that if potential or efficiency are fixed in time, one is either unable to measure socio-economic system's potential or efficiency.

In order to estimate the range of efficiency for resources performance on the basis of acquired data, we performed wavelet transformation on the basis of original

signal. According to the recommended procedure (Astafijeva, 1996; Chun-Lin, 2013; Mallat, 1998), continuous wavelet transform is carried out by convolution of the analyzed signal (function) from twoparametrical wavelet function (se Eq. 1).

$$
\begin{aligned}
& W(a, b)=\int_{-\infty}^{\infty} f(t) \cdot \psi_{a, b}^{*}(t) d t \\
& \psi_{a, b}^{*}(t) \text { is a complex interfaced volume. }
\end{aligned}
$$

Anna Svirina, Elena Parfenova and Olga Shindor (2016), Journal of Economics Studies and Research, DOI: $10.5171 / 2016.831476$ 
The basis of wavelet transform is derived from the mother wavelet by means of scaling and shifting (see Eq.2).

$\psi_{a, b}=\frac{1}{\sqrt{a}} \psi\left(\frac{t-b}{a}\right)$

a - the large-scale coefficient defining the width of a wavelet, $b$ - the shift parameter defining the provision of a wavelet on an axis $\mathrm{t}$.

Wavelet transform allows to analyze the thin structure of signals as the mobile time-andfrequency window, which equally well marks out low frequency and high frequency signal components and thus have a big advantage over the analysis of signals' local features - the latter are absent at Fourier's transformation.

For the purposes of this study, we have chosen Morlet wavelet, which has narrow spectral range and considerable duration in a time domain (see Eq.3):

$\psi(x)=e^{-x^{2} / 2} \cdot \cos (5 x)$

This mother wavelet suits best the basic purpose of the study as it allows evaluating long periods of time and the narrow range of the basic independent variable.

\section{Main Findings}

When time is viewed as an independent variable for economic cycle modeling, one should explain why cycles of the same type differ significantly in terms of their duration. For example, a Kondratiev wave can last from 40 to 60 years (Korotayev \& Tsirel, 2009). Thus, such models would have little accuracy in predicting the beginning of the next stage or the next cycle because the maximum duration of the cycle is 1.5 times greater than its minimum duration. This point has been discussed in a number of studies (Rothbard, 1984). The same feature inheres in other types of business cycles: a Kitchin cycle can last from 3 to 4 years (33\% deviation between minimum and maximum duration), a Juglar cycle can last from 7 to 11 years (57\% deviation), and a Kuznets cycle can last from 15 to 25 years $(66.7 \%$ deviation). Thus, the average error of the prognosis model based on a time-based business cycle model is $51.68 \%$, which is unacceptably high for a model. This leads to a conclusion, that time is possibly only a descriptive statistical measure that can be used to describe economic cycles, and can not be viewed as an independent variable hence, a predictor which would allow evaluating economic cycles, is necessary.

According to our previous research (Svirina et. al, 2014), conversion point from classical to quantum economy is defined in our opinion by the ratio between the volumes of real and financial sectors of the economy: in case there is parity between those, the laws of classical economy operate; if these sectors are highly disproportional - the laws of quantum economics start operating. This can be formalized in the following way (see Eq.4):

$M V=P Q+\hbar^{*} P Q=P Q *(1+\hbar)$

where $M V$ - the volume of stock of money and quasi-money (financial aggregates) corrected by the turnover speed of this total stock, monetary units; $P Q$ - the volume of real sector of the economy, defined as a sum of goods and services produced, corrected by the price, monetary units; $\hbar$ - parameter, characterizing disproportion between the financial and real sectors of the economy.

Such approach allows eliminating the problem of immeasurability of financial sector volume at a certain time point.

For the purposes of this study we have estimated the ratio between the financial and real sectors of economy volume as a possible predictor of economic crisis, and evaluated the data on the US financial and real sector volumes from 1867 to 2013. GDP was viewed as the volume of real sector, while the financial sector volume was estimated as the turnover of financial institutions and quasi-monetary instruments, acquired from the open source (US Bureau of Census, 2014). The evaluation of this ratio on a time-scale can be seen on Figure 2 


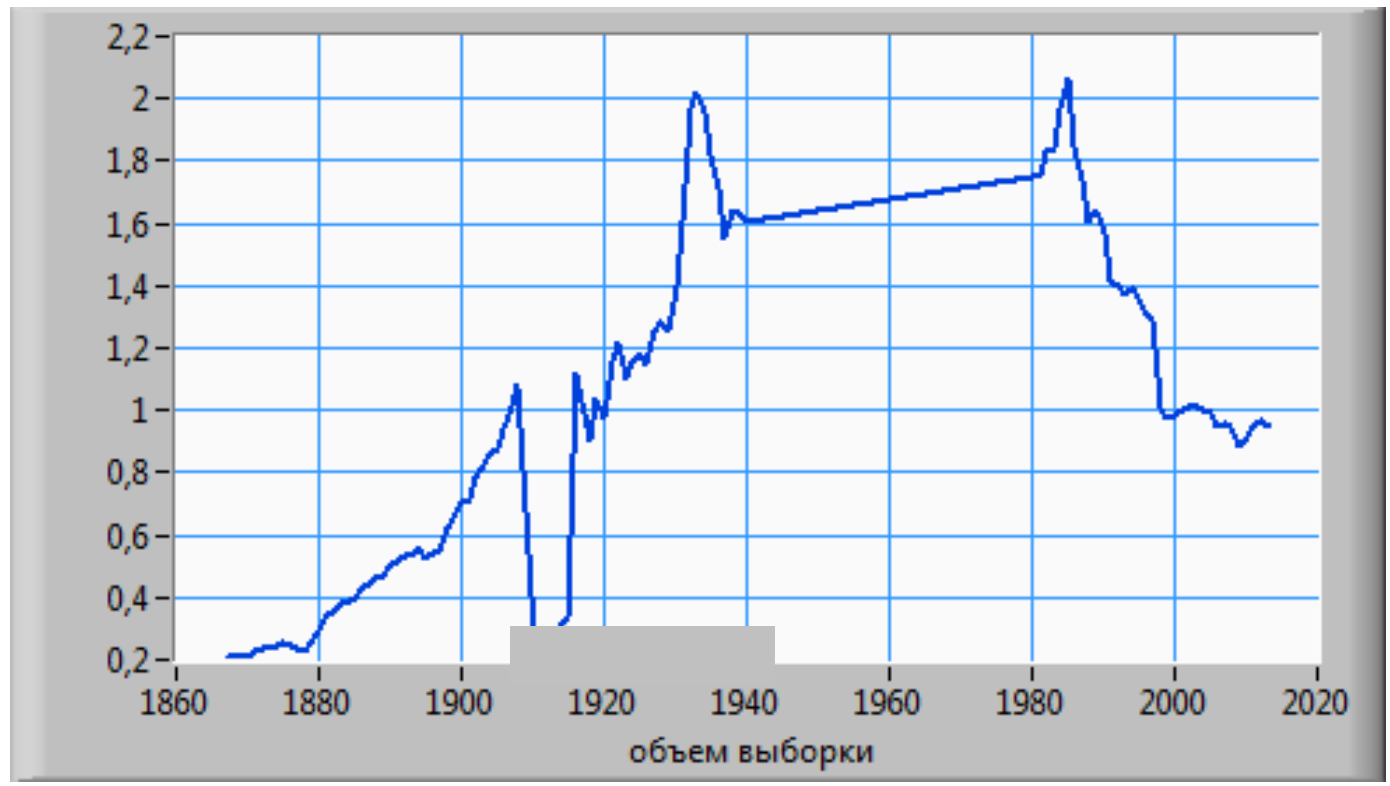

Figure 2: Dynamics of financial/real sector of economy ratio

As it can be seen from Figure 2, direct evaluation of the suggested predicting factor does not allow revealing any tendency; corresponding results were achieved on the basis of correlation analysis. Visual comparison of financial/real sector ratio to GDP also does not show any kind of trend to predict economic crisis (see Figure 3).

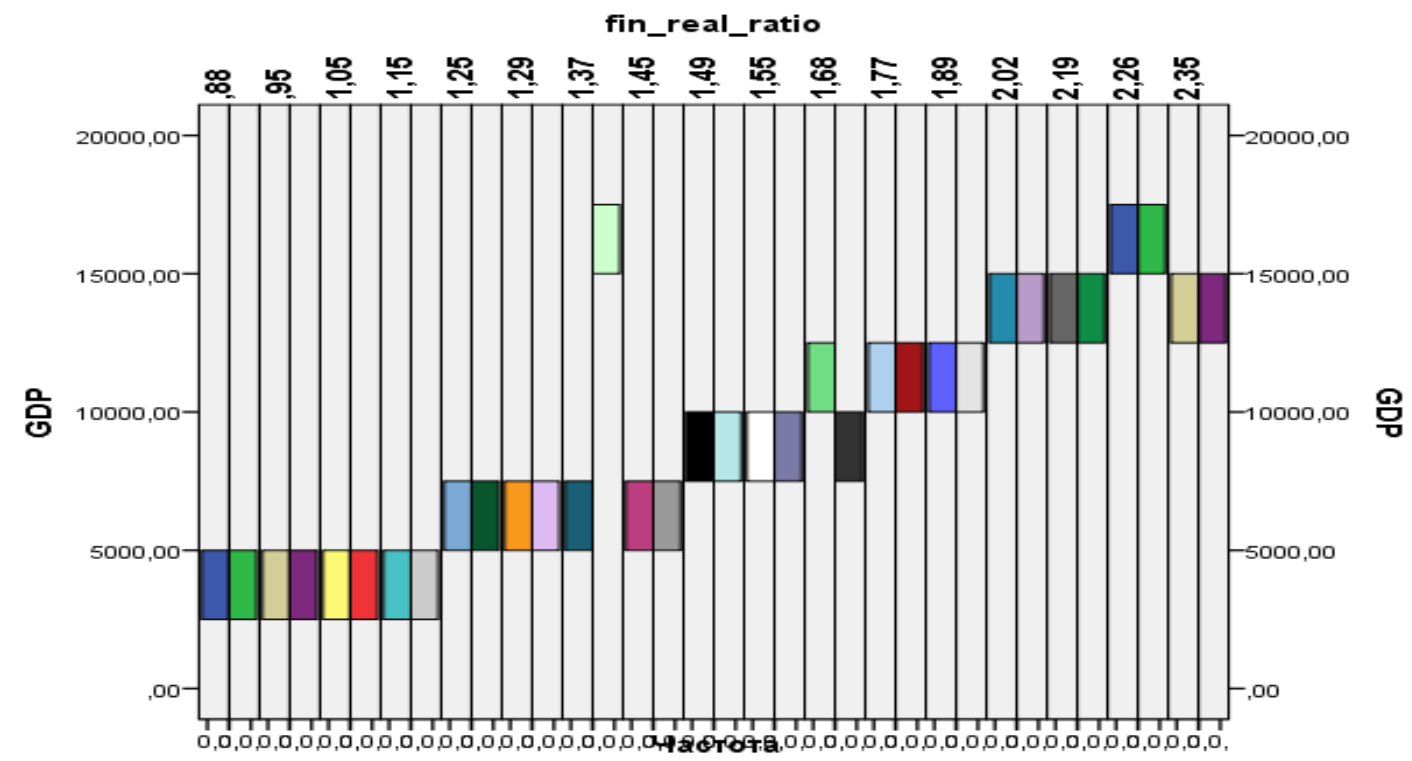

Figure 3: GDP-financial/real sector ratio X-chart

Thus, we applied the above described approach based on wavelet analysis to estimate whether the processing of the signal (financial/real sector ratio) would allow estimating the tendency to predict the possibility of economic crisis in the case of the US. The results of the analysis performed with Morlet wavelet are presented in Fig. 4 
(starting 1867). To implement this analysis, we propose that changes in the financial sector occur with high level of uncertainty as stated by Heisenberg (1927).

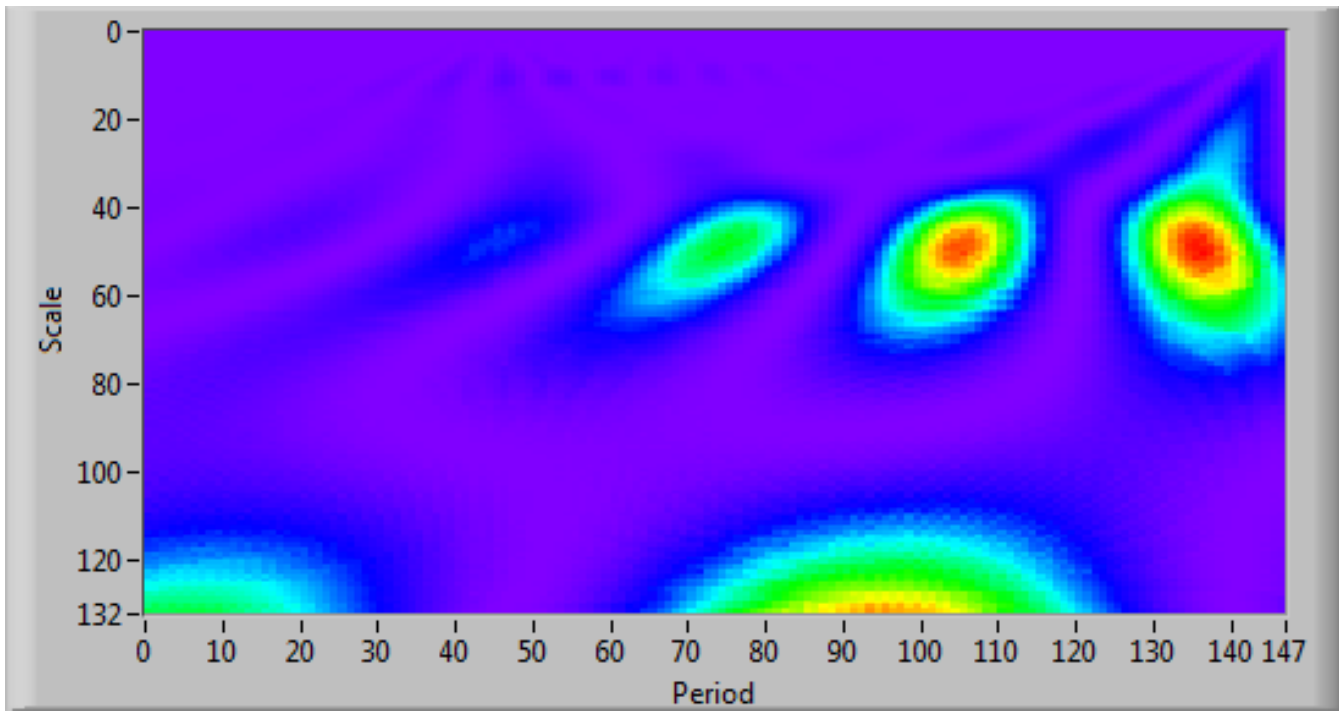

Figure 4: Scalogram of financial/real sector of the economy ratio (US data) along the timeline

As it can be seen from Figure 4, financial/real sector ratio can serve as predictor of major economic crises: on the scalogram at the level of 50 (which evaluates intensity), one can see three visualized versions of the crisis: first one appears from year 60 to 80 (1927-1947) which reflects the Great Depression and the World War II, the red center of the oval-shaped figure which refers to the upcoming Energy crisis, and the final red-centered figure which refers to the economic crisis of 2007-2013. However, the predictor indicates the start of crises at an earlier stage than it had revealed (1927 for the Great Depression, 1967 for the Energy crisis and 2004 for the last financial crisis) thus, we can consider this predictor to evaluate the upcoming crisis with higher probability than the existing tools. It is also worth mentioning that wavelet transform also allows evaluating intensity: it can be seen from Figure 4 that the last economic crisis appeared to be more intensive than the Great Depression or the Energy crisis.

Thus, we suggest that the economic cycle stage (regarding long term cycles) is defined by the ratio of real to financial sector volumes. A growth stage is observed when there is parity between the two sectors, meaning that the amount of consumption within the economic system is equal to the amount of investment. A recession begins when the financial and real sectors become highly unbalanced; this is in line with the findings of Cecchetti and Kharroubi (2015), who captured the quantitative proof of such imbalance.

One can also notice bigger shapes on 130 levels of intensity, which we consider to be long waves reflecting changes in economic formations, but the limited data which are used for this study do not allow making justified conclusions on the issue.

\section{Discussion and Limitations}

The first finding of our study, which has theoretical implications, is the suggested quantum approach towards economic crisis possibility estimation, which evaluates the financial sector as the one changing with the level of volatility that can not be explained within deterministic paradigm. The second finding which enriches existing literature in economic crisis evaluation by suggesting to use financial/real sector volume ratio as a predictor of economic crisis along with wavelet transform, which reveal certain tendencies on the global level. The third finding of the paper is the use of wavelet transform to evaluate economic data, which can provide research with the results that 
can not be identified by traditional methods. Finally, the proposed approach allows foreseeing economic crisis 4-5 years prior to active stage of the crisis, thus the implication to practice is acquiring extra time to prepare for the crisis, and in certain cases to propose regulation changes to avoid major problems in country development.

The main limitation of the study is that we used only the data on the US financial and real sectors of the economy, hence our findings may be relevant only to this country's economy rather than be a universal trend. The second limitation comes from the sources of data: the financial sector of the US was evaluated between 1967 and 2014 , but the structure of this sector, which might affect the estimated volume, had changed significantly during 147 years hence a few assumptions were made to provide financial volume assessment with the same methodology along this timeline. Though measures were taken to decrease possible mismatches, these could appear and decrease the significance of the findings.

According to the limitations' state, the following trends for future research can be estimated. First, the findings are to be tested with the data from other countries besides the US along the same timeline. Second, alternative methods of financial sector volume estimation are to be considered to eliminate the possibility of inadequate estimation along the timeline. Third, it should be investigated, what type of crisis appears on the higher levels of intensity, as this possibly might be a change of economic formations.

Further research should also address the time issue and evaluate the possibility that relativity laws from quantum physics also apply to economic situations, thus distorting the understanding of economic agents on the time left to upcoming crises.

\section{Acknowledgement}

This research was carried out under Russian Fund for Fundamental Research (RFFI) grant program, grant 14-06-00350 "Evaluation of the hypothesis on possible quantum nature of economic environment and economic cycles".

\section{References}

1. Astafijeva, N.M. 1996. Wavelet analysis: basic theory application examples. Successes in Physical Sciences. No 11, p.1145.- 1170

2. Boero, G., Smith, J., Wallis, K. 2008. Uncertainty and Disagreement in Economic Prediction: The Bank of England Survey of External Forecasters. The Economic Journal, Vol. 118, No. 530, pp. 1107-1127

3. Cecchetti, S., Kharroubi E. 2015. Why does financial sector growth crowd out real economic growth? Retrived from https://www.bis.org/publ/work490.pdf

4. Cencini A. 2001. Monetary Macroeconomics. A New Approach. New York: Routledge. pp. 63-84.

5. Chun-Lin, L. 2013. A Tutorial to Wavelet Transform. Retrieved from http://disp.ee.ntu.edu.tw/tutorial/WaveletT utorial.pdf

6. Downey, K., Slocum, J. 1975. Uncertainty: Measures, Research, and Sources of Variation. Academy of Management Journal. No 18. pp. 562-578.

7. Eusepi S., Preston B. 2011. Expectations, Learning and Economic cycle Fluctuations. American Economic Review 101

8. Goncaves, C. 2012. Chaos and Nonlinear Dynamics in Quantum Artificial Economy. 2012. arXiv:1202.6647v1 29Feb2012.

9. Hansen A.H. 1951. Business Cycles and National Income. Norton publishing.

10. Heisenberg, W. 1927. "Über den anschaulichen Inhalt der quantentheoretischen Kinematik und Mechanik", Zeitschrift für Physik (in German) 43 (3-4): 172-198

11. Jurado, K., Ludvigson, S., Ng, S. 2013. Measuring Uncertainty. Retrieved from http://www.econ.nyu.edu/user/ludvigsons/ vol.pdf

12. Kondraty'ev N.D. 1989. Problemy Ekonomicheskoy Dinamiki. Moscow: Economica. 
13. Kuznets S. 1965. Economic Growth and Structure: Selected Essays. New York: Norton

14. Lev, B. 1975. Environmental Uncertainty Reduction by Smoothing and Buffering: An Empirical Verification. Academy of Management Journal. No 18. pp. 864-871.

15. Lorsch J., Allen S. 1973. Managing Diversity and Interdependence: An Organizational Study of Multidivisional Firms. Boston: Harvard University Graduate School of Business Administration, Division of Research

16. Mallat, S. 1998. A wavelet tour of signal processing. Academic Press

17. Marx K. 1990. Capital: Critique of Political Economy. London: Penguin Books 18. Schumpeter J. 1939. Economic cycles: A theoretical, historical and statistical analysis of the Capitalist process. Eastford: Martino Publishing

19. Sobey C. 2012. A Model of Quantum Economic Development.

http://mpra.ub.uni-muenchen.de/36422/
20. Studwell J. 2013. How Asia Works. London: Profile Books.

21. Svirina A., Parfenova E., Shurkina E. 2014. The Nature of Business Cycles: a Quantum Approach. Proceedings of 24th International Business Information Management Association Conference, Milan, Italy, November 6-7, 2014. pp. 755-763.

22. Sweeney, W., Kenyon, D., Kramer, R. 1987. Toward an Appropriate Measure of Uncertainty in a Risk Programming Model. American Journal of Agricultural Economics, Vol. 69, No. 1, pp. 87-96

23. Ternyik S. 2012. The Monetary Quantum. 2012.

http://mpra.ub.uni-muenchen.de/41973/

24.Uncertainty principle. 2013. Retrieved from

http://abyss.uoregon.edu/ js/21st_century _science/lectures/lec14.html

25. US Bureau of Census. 2014. Historical Statistics of the United States. Federal Reserve Bank at St.Louis. 